\title{
Knowledge and Attitude towards Smoking among Fayoum
}

\section{University Students}

\author{
Naglaa A El Sherbiny*, Assem El Essawy**, Ekram M Abdel Khalek**
}

\begin{abstract}
Smoking is a behavioral cause of premature morbidity and mortality, resulting in approximately four million persons dying of smoking-related diseases annually worldwide. This study aims to investigate the extent of smoking habit, knowledge toward smoking among Fayoum University students. A cross sectional analytical study was conducted in Fayoum University during the academic year 2010. A total of 804 students were selected by using randomized multi-stage sampling using self-administered questionnaire for data collection. Data were analyzed using SPSS version 16. The respondents age ranged from 18 to 26 years $20.36 \pm(1.21)$ years. The males were $51 \%(n=410)$ and females were $49 \%(n=394)$. The prevalence of smoking among students was $13.4 \%$. a large percentage of the smokers $82.4 \%$ used cigarettes while $8.3 \%$ smoked water pipe. Regarding knowledge about smoking related diseases, $97.3 \%$ of the students knew that smoking causes diseases; but only $5.6 \%$ of the sample had good/and satisfactory knowledge score about the causal role of tobacco in the development of specific diseases, and $66.7 \%$ of smoker students want to quit with a higher intention of for older group. In conclusion, smoking is prevalent among the university students and their knowledge about the harmful effects of smoking is generally superficial. Definite counseling programs are greatly needed to help students quit smoking.
\end{abstract}

Key words: Smoking; university students; knowledge; attitudes

\section{INTRODUCTION}

Smoking is the most important preventable

cause of death, there are 4 million persons

dying of smoking-related diseases annually.

The annual mortality will exceed ten million

during the 2020s. The prevalence of smoking

in African countries ranged from $17 \%$

to $32 \%$.(1) US Department of Health and
Human Services reported that $48 \%$ of men and $7 \%$ of women in developing countries smoke. While in industrialized countries, $42 \%$ of men and $24 \%$ of women smoked.(2) The harmful effects of cigarette smoking are destructive and widespread. Smoking affect, nearly every organ in the body and 
half of all long-term smokers die cost-effective preventive intervention that prematurely from smoking-related disease. can offer to smoker person. ${ }^{(7)}$ Helping For every person who dies from tobacco smokers to stop smoking should be the use, another 20 suffer; with at least one serious tobacco-related illness. (3) goal of every health professional through motivational process. ${ }^{(8)}$ This process begins According to CDC report; $80 \%$ of adult smokers begun smoking before the age of 18 years and every day, nearly 3000 young people become regular smokers.(3) If there is no action plan to stop initiate smokers, more than 5 million children will die prematurely because of future smoking as adolescents. Tobacco smoking among youth is a serious health issue in Egypt as it is reported that smoking prevalence among overall youth is $19.6 \% .^{(4)}$ University students are at high risk of smoking as they become exposed to smoking peers and face social, emotional and educational challenges. (5) Knowledge about the dangers of smoking was a predictor of smoking behavior; and risk awareness alone seems to be insufficient to stop smoking. ${ }^{(6)}$ during the academic year 2010. The Smoking cessation is the most important, suggested prevalence of smoking among 
Egyptian youth aged 15 to 24 years according to the Demographic Health Survey 2008 was $6.2 \%{ }^{(10)}$ The study population consisted of a sample of 804 male and female students out of total Fayoum University students of 25,000 which was randomly drawn from different faculties. Sample was selected by multistage random sample technique. The fundamental criteria for sample selection included: students aged 18-26 years. An attempt was made to include representative proportions of male/female and junior /senior students. A total of 850 questionnaires were distributed among different faculties in Fayoum University. Full participation (total= 804) with a respondent rate of $94.6 \%$ was obtained. The students completed a self-administered Arabic questionnaire consisting of 21 items. The first six questions were demographics questions. seven questions about smoking experience pattern of smoking, and age of initiation, and the last eight questions were about knowledge of smoking related diseases concerning various risk factors as well as willing to quit.
The questionnaires were administered and collected in the same setting.

This study was reviewed and approved by the Faculty of Medicine Research Ethical Committee, and a waiver of consent form was approved. We used an anonymous questionnaire with no private or sensitive information. Before distributing the questionnaire, the researcher informed the students about the objectives of the study, and the confidentiality of their information. All participants had the right not to participate in the study.

Data were analyzed using SPSS software version 16, simple descriptive analysis in the form of means and standard deviations were calculated for numerical data. Qualitative data were described using percent distribution and chi square test. Inferential statistic test was used to detect differences between categories, with a significant level of less than 0.05 .

Scoring of the knowledge was done where we the correct answer was scored 1 
and the false or don't know answers were

scored 0 . The knowledge score was computed by summing all correct responses. Categorization of the knowledge was done as follows:

- Poor knowledge was considered if $<50 \%$ of questions were answered correctly.

- Satisfactory knowledge was considered if from $50 \%$ to $75 \%$ of questions were answered correctly.

- Good knowledge was considered if $>75 \%$ of questions were answered correctly.

\section{RESULTS}

In the present study, from 804 participating students, male respondents were $51 \%(n=410)$ and females were $49 \%$ $(n=394)$, the students age ranged from 18 to 26 years with a mean $( \pm S D$ ) of 20.36 $( \pm 1.21)$ years. A $58.8 \% \quad(n=470)$ of the students were from urban areas, while $41.2 \% \quad(n=334)$ were in rural areas residency. The Applied sciences faculties represented $60.7 \%$ of the study sample (Faculty of Medicine, Faculty of
Engineering and Faculty of Sciences), wheyeas the theoretical faculties represented $39.8 \%$ (Faculty of Tourism, Faculty of Arts and Faculty of Social Work). The students were mainly in second, third and fourth grades $92.4 \%(n=743)$ as seene in Table 1.

The prevalence of smoking among Fayoum University students was $13.4 \%$ (26.3\% in male and $0 \%$ in female). The majority of the smokers (82.4\%) used cigarettes while $8.3 \%$ smoked water pipe. The average age of smoking initiation ranged from 12 to 22 years with a mean \pm SD of $17.73 \pm$ 1.99 years. The period of smoking ranging from 1 to 11 years with a mean $\pm S D$ of $2.87 \pm 1.85$ years. The numbers of cigarette smoking per day ranged from 1 to 40 with a mean $\pm S D$ of $11.05 \pm 6.66$ cigarettes and less than two thirds of smokers were moderate smokers as they consumed 10-20 cigarettes per day (Table 2).

A total of 439 (54.6\%) of the students' families, one or more members were currently smoking 
$369(84.1 \%)$ of which were cigarette smokers and, $182(41.5 \%)$ of which were suffering from smoking related diseases such as chest disease (88.02\%), heart diseases (8.2\%), peptic ulcer $(2.7 \%)$, osteoporosis $(2.7 \%)$ and liver diseases (1.1\%).

As regards knowledge about smoking related diseases, $(n=782)(97.3 \%)$ of the study sample knew about harmful effect of smoking in developing different diseases such as cancer, chest and heart diseases. Regarding the source of information, the students took their knowledge about smoking hazards mainly from mass media $(62.4 \%)$, followed by learning about smoking hazards from their studi programs (19.7\%). Also, health facilities and friends were considering as effective source of information (19.4\% and $18.4 \%$, serpetively as shown in Table 4.

Figure 1 illustrates the score of knowledge about the causal role of tobacco in the development of specific diseases, only $1.7 \%$ of participants had good knowledge, $3.9 \%$ their knowledge was satisfactory while the majority $94.4 \%$ had poor knowledge.

Good/satisfactory level of knowledge about smoking health hazards was relatively more among age group 18-20 years, urban residents, students in applied sciences faculties and tobacco smokers. These differences are statistically significant $(P<0.05)$. as showe in Table 5. While $72(66.7 \%)$ of smoker students intended to attempt quitting smoking, $36(33.3 \%)$ of them were not intended to do so even theugh they know its health hazasds. The positive attitude of quitting is statistically significant among older age group (21-26) while no significaut difference was found fer the other studied vairiables (residence, focety type and knowledye score.

\section{DISCUSSION}

Smoking and the use of other tobacco products has been linked to a wide range of detrimental health outcomes including cancer, cardiovascular disease and respiratory illness. 
WHO (2008) (11) estimates that $50 \%$ of misconceptions regarding its use, for instance smokers in Egypt will die of tobacco-related that nicotine content is lower than that of diseases. In addition, a growing number of cigarettes and that water filters out all the Egyptian youth smoke Shisha (traditional water pipe), under the mistaken impression that it is less harmful.

The overall smoking prevalence of Egyptians aged $10-29$ years is $26 \%$. The majority of those who smoke are males in the age category 18-29.(12) The results of our study showed a smoking prevalence of $26.3 \%$ of male university students, which is almost the same as the overall national level, but lower than the prevalence of current smokers in Ain Shams University (31.5\%).(13)

The majority of the smokers (82.4\%) used cigarettes while $(8.3 \%)$ smoked water pipe (Shisha). In a study of tobacco prevalence among Health Sciences College students in Riyadh, $33 \%$ of males and $6 \%$ of females smoked cigarettes and $30 \%$ of males and $5.6 \%$ of females smoked Shisha(14). The increasing trend of Shisha smoking observed in the last decade is accredited to the noxious chemicals.

In the present study, there was no female smokers which was in agreement with a study of 600 hostel residents of Alexandria University where $17.5 \%$ of males and $0 \%$ of females were current smokers. ${ }^{(15)}$ In a survey of 559 students University of Cairo aged 15-27 years, $22 \%$ were current smokers, compared with $1.7 \%$ of females who were current smokes. ${ }^{(16)}$ Female smoking is less in Upper Egypt because the culture prohibits female smoking and this is governed by the claimed male superiority present in this culture and supported by the social stigma associated with female smoking.

The mean age of smoking initiation \pm SD is $17.73 \pm 1.99$ years and $92.6 \%$ of students started smoking before age of twenty. The period of smoking ranging from 1 to 11 years with $73.1 \%$ smoked for $1-3$ years and less than two thirds of smokers were moderate 
smokers as they consumed $10-20$ cigarettes per day. The previous findings are nearly similar to those found by Youssef et al.,(2002) ${ }^{(17)}$ who reported that the mean age of smoking initiation was 18.1 years. But Yorulmaza et al., (2002) (18) found that the age of smoking onset of Turkish adolescents was $13.02 \pm 2.78$ years, the average smoking rate of the smokers was $5.65 \pm 5.89$ cigarettes/ day and the mean duration of smoking was $3.07 \pm$ 2.63 years.

Regarding knowledge about smoking related diseases our results revealed that $97.3 \%$ of respondents knew the effect of smoking in developing different diseases. However, the knowledge score about the causal role of tobacco in the development of specific diseases is poor in $94.4 \%$ of the students and the main source of their knowledge is the mass media $(62.4 \%)$. This finding is below the mean knowledge score percentage of smoking among members of university students' unions in Ain Shams University was $79.4 \pm 20.7$. (13) $^{\text {In Riyadh, }}$ around $86 \%$ of smokers were found to have more knowledge about the harm of tobacco use and their families and friends were the main sources of this knowledge. ${ }^{(14)}$

In our study, $66.7 \%$ of smoker students want to quit and this attitude is higher among older age group (21-26). This finding is similar to the result of public health research consortium that $67 \%$ of male and $76 \%$ of female (20-24) years old regular smokers) want to give up.(19) In another study, Glantz and Jamieson. (20) found that the majority of young smokers report that they want to quit, and the prevalence of ex-smokers increases with age among 16-24 year olds. Abolfotouh reported that among 44 smokers students in Alexandria University Hostels, 90.1\% wanted to reduce their smoking as a first step to quit.(15)

\section{CONCLUSION AND RECOMMENDATIONS}

This study concluded that smoking is prevalent among Fayoum University students. The knowledge of the harmful effects of smoking is generally poor. 
- An intensive anti-smoking educational program aimed at changing behavior and attitude of tobacco smoking.

- Opening of smoking cessation clinic in the University hospital to help students in quitting with a motivational counseling sessions.

- Activation of policy and regulation to reduce youth access to tobacco products.

- Introducing teaching information about dangerous effect of smoking in the school and university curricula.

Table 1: Personal characteristics of Fayoum University studied students

\begin{tabular}{|c|c|c|c|c|c|}
\hline Variables & $\begin{array}{c}\text { Male } \\
\text { Students } \\
\mathrm{n}=410\end{array}$ & $\%$ & $\begin{array}{c}\text { Female } \\
\text { students } \\
n=394\end{array}$ & $\%$ & $P$ value \\
\hline \multicolumn{6}{|l|}{ Age groups } \\
\hline $18-20$ & 207 & 50.5 & 264 & 67.0 & \multirow[t]{2}{*}{$0.000^{*}$} \\
\hline $21-26$ & 203 & 49.5 & 130 & 33.0 & \\
\hline \multicolumn{6}{|l|}{ Residence } \\
\hline Urban & 241 & 58.8 & 229 & 58.1 & \multirow[t]{2}{*}{0.453} \\
\hline Rural & 169 & 41.2 & 165 & 41.9 & \\
\hline \multicolumn{6}{|l|}{ Faculty Types } \\
\hline Applied sciences & 296 & 72.2 & 192 & 48.7 & \multirow[t]{2}{*}{$0.000^{*}$} \\
\hline Theoretical & 118 & 27.8 & 202 & 51.3 & \\
\hline
\end{tabular}


Table 2: Smoking prevalence and pattern among Fayoum University studied students

\begin{tabular}{|c|c|c|}
\hline & No. $(n=108$ male) & $\%$ \\
\hline \multicolumn{3}{|c|}{ Currently smoking $(n=804)$} \\
\hline Yes & 108 & 13.4 \\
\hline No & 696 & 86.6 \\
\hline \multicolumn{3}{|l|}{ Type of smoking } \\
\hline Male smokers & $108 / 410$ & 26.3 \\
\hline Cigarette & 89 & 82.4 \\
\hline Water Pipe (Shisha) & 9 & 8.3 \\
\hline Both & 10 & 9.3 \\
\hline \multicolumn{3}{|l|}{ Age of start in years } \\
\hline Less than 15 & 6 & 5.6 \\
\hline $15-20$ & 94 & 87.0 \\
\hline More than 20 & 8 & 7.4 \\
\hline Mean \pm SD (Range) & \multicolumn{2}{|c|}{$17.73 \pm 1.99(12-22)$} \\
\hline \multicolumn{3}{|c|}{ Duration of smoking in years } \\
\hline $1-3$ & 79 & 73.1 \\
\hline 4 or more & 29 & 26.9 \\
\hline Mean \pm SD (Range) & \multicolumn{2}{|c|}{$2.87 \pm 1.86(1-11)$} \\
\hline \multicolumn{3}{|c|}{ Daily cigarette consumption/ day } \\
\hline Less than 10 & 36 & 33.3 \\
\hline $10-20$ & 68 & 63.0 \\
\hline More than 20 & 4 & 3.7 \\
\hline Mean \pm SD & \multicolumn{2}{|c|}{$11.05 \pm 6.66(1-40)$} \\
\hline
\end{tabular}

Table 3: Smoking related diseases among Fayoum University studied students' families

\begin{tabular}{|c|c|c|}
\hline & No. & $\%$ \\
\hline \multicolumn{3}{|c|}{ Currently smoking $(n=804)$} \\
\hline Yes & 439 & 54.6 \\
\hline No & 365 & 45.4 \\
\hline \multicolumn{3}{|c|}{ Type of smoking $(n=439)$} \\
\hline Cigarette & 369 & 84.1 \\
\hline Water Pipe (Shisha) & 51 & 11.6 \\
\hline Both & 19 & 4.3 \\
\hline \multicolumn{3}{|c|}{ Suffering from smoking related diseases $(n=182)$} \\
\hline Chest diseases & 160 & 88 \\
\hline Heart diseases & 15 & 8.2 \\
\hline Osteoporosis & 5 & 2.7 \\
\hline Peptic ulcer & 5 & 2.7 \\
\hline Liver diseases & 2 & 1.1 \\
\hline
\end{tabular}


Table 4: Knowledge of students about smoking related diseases

\begin{tabular}{|l|c|c|}
\hline & No. $(\mathbf{n}=\mathbf{8 0 4})$ & \% \\
\hline Knowledge of smoking related diseases & 782 & 97.3 \\
\hline Cancer & 619 & 77.0 \\
\hline Chest diseases & 566 & 70.4 \\
\hline Heart diseases & 344 & 42.8 \\
\hline Impotence & 123 & 15.3 \\
\hline T.B & 103 & 12.8 \\
\hline Liver diseases & 81 & 10.1 \\
\hline Hypertension & 80 & 10.0 \\
\hline Gum diseases & 62 & 7.7 \\
\hline Peptic ulcer & 51 & 6.3 \\
\hline Decrease body immunity & 50 & 6.2 \\
\hline Renal diseases & 29 & 3.6 \\
\hline Osteoporosis & 29 & 3.6 \\
\hline Anemia & 23 & 2.9 \\
\hline Psychiatric problems & 15 & 1.9 \\
\hline Death & 15 & 1.9 \\
\hline Source of information & \multicolumn{2}{|l|}{} \\
\hline Mass Media & 502 & 62.4 \\
\hline Study about smoking hazards & 158 & 19.7 \\
\hline Health facilities information & 156 & 19.4 \\
\hline Friends & 148 & 18.4 \\
\hline
\end{tabular}

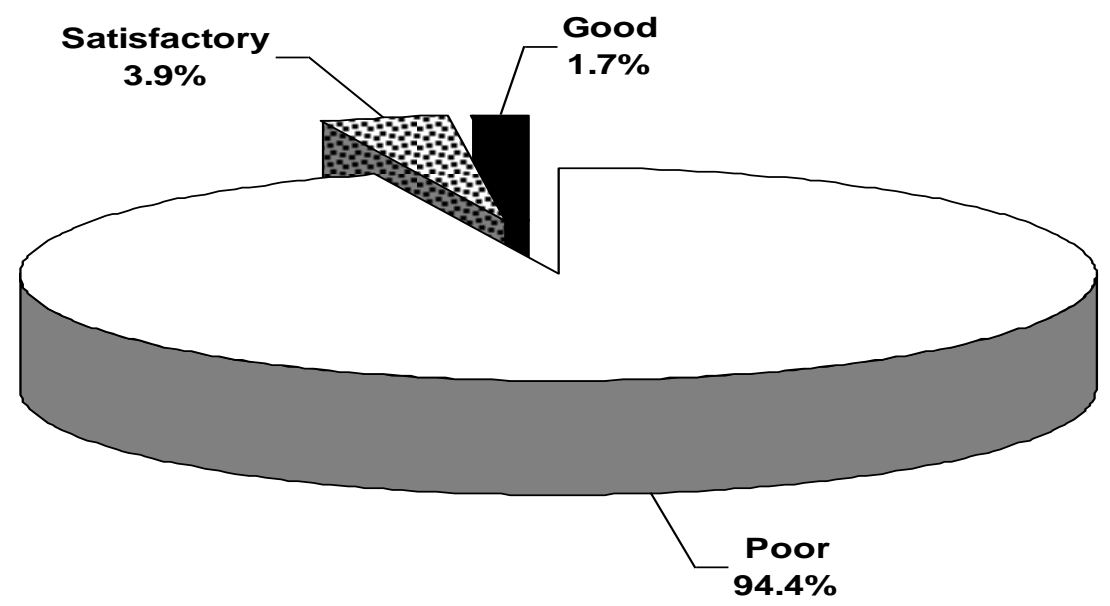

Figure 1: Distribution of the students according to their smoking knowledge score 
Table 5: Relationship between score of knowledge and personal characteristics.

\begin{tabular}{|c|c|c|c|c|c|}
\hline \multirow{3}{*}{ Socio-demographic characteristics } & \multicolumn{4}{|c|}{ Score of knowledge about smoking } & \multirow{3}{*}{ P-value } \\
\hline & \multicolumn{2}{|c|}{$\begin{array}{c}\text { Poor } \\
(n=759)\end{array}$} & \multicolumn{2}{|c|}{$\begin{array}{l}\text { Satisfactory/ Good } \\
\qquad(n=45)\end{array}$} & \\
\hline & No. & $\%$ & No. & $\%$ & \\
\hline \multicolumn{5}{|l|}{ Sex } & \multirow{3}{*}{0.550} \\
\hline Male & 389 & 94.9 & 21 & 5.1 & \\
\hline Female & 370 & 93.9 & 24 & 6.1 & \\
\hline \multicolumn{5}{|l|}{ Age in years } & \multirow{3}{*}{$0.003^{*}$} \\
\hline $18-20$ & 435 & 92.4 & 36 & 7.6 & \\
\hline $21-26$ & 324 & 97.3 & 9 & 2.7 & \\
\hline \multicolumn{5}{|l|}{ Residence } & \multirow{3}{*}{$0.000^{*}$} \\
\hline Urban & 432 & 91.9 & 38 & 8.1 & \\
\hline Rural & 327 & 97.9 & 7 & 2.1 & \\
\hline \multicolumn{5}{|l|}{ Faculty type } & \multirow{3}{*}{$0.000^{*}$} \\
\hline Applied sciences & 443 & 90.8 & 45 & 9.2 & \\
\hline Theoretical & 316 & 100.0 & 0 & 0.0 & \\
\hline \multicolumn{5}{|l|}{ Smoking } & \multirow{3}{*}{$0.026^{*}$} \\
\hline Smoker & 97 & 89.8 & 11 & 10.2 & \\
\hline Non-smoker & 662 & 95.1 & 34 & 4.9 & \\
\hline
\end{tabular}

Table 6: Relationship between attitude towards quitting of smoking and personal characteristics.

\begin{tabular}{|c|c|c|c|c|c|}
\hline \multirow{3}{*}{ Personal characteristics } & \multicolumn{4}{|c|}{ Desire to quitting } & \multirow{3}{*}{ P-value } \\
\hline & \multicolumn{2}{|c|}{$\begin{array}{c}\text { Yes } \\
(n=72)\end{array}$} & \multicolumn{2}{|c|}{$\begin{array}{c}\text { No } \\
(n=36)\end{array}$} & \\
\hline & No. & $\%$ & No. & $\%$ & \\
\hline \multicolumn{5}{|l|}{ Age in years } & \multirow{3}{*}{$0.038^{*}$} \\
\hline $18-20$ & 37 & 58.7 & 26 & 41.3 & \\
\hline $21-26$ & 35 & 77.8 & 10 & 22.2 & \\
\hline \multicolumn{5}{|l|}{ Residence } & \multirow{3}{*}{0.241} \\
\hline Urban & 52 & 70.3 & 22 & 29.7 & \\
\hline Rural & 20 & 58.8 & 14 & 41.2 & \\
\hline \multicolumn{5}{|l|}{ Faculty type } & \multirow{3}{*}{0.467} \\
\hline Applied sciences & 47 & 64.4 & 26 & 35.6 & \\
\hline Theoretical & 25 & 71.4 & 10 & 28.6 & \\
\hline \multicolumn{5}{|c|}{ Score of knowledge about smoking } & \multirow{3}{*}{0.070} \\
\hline Poor & 64 & 88.9 & 33 & 91.7 & \\
\hline Satisfactory/ Good & 8 & 11.1 & 3 & 8.3 & \\
\hline
\end{tabular}

Chi-square test

${ }^{*}$ Statistical significant difference $(P<0.05)$ 


\section{REFERENCES}

1. Koffi N, Kouassi B, Horo K. Smoking in the African setting (Abidjan, Ivory Coast): patient knowledge, attitude and behavior. Rev. Pneumol Clin 2004; 60 (4): 217-22.

2. US Department of Health and Human Services. The health consequences of smoking: A report of the Surgeon General. Atlanta: U.S. Department of Health and Human Services, Centers for Disease Control and Promotion, Office on Smoking and Health 2004.

3. CDC. Best Practices for Comprehensive Tobacco Control Program. Centers for Disease Control and Prevention.[cited 2007] Available frtom: www.cdc.gov/tobacco.

4. Global Youth Tobacco Survey Collaborative Group. Egypt GYTS Fact Sheet. [cited 2002]Available from: http://www.cdc.gov/Tobacco/global/gyts/ GYTS factsheets.htm.

5. Nargis AL, Abeer AB, Naglaa ES, Eman $\mathrm{H}$. Stress profile among Fayoum University Students. Master thesis. Fayoum nuiversity; 2010.

6. Khalid MA.Tobacco Prevalence among Health Sciences College Students (HSC) : Riyadh, Saudi Arabia World Family Medicine Journal. 2010; August (8), Issue

7. US Public Health Service Report. Tobacco use and dependence clinical practice guideline panel, staff, and consortium representatives: A clinical practice guideline for treating tobacco use and dependence. JAMA.2000; 283: 3244-54.

8. Jacques $\mathrm{C}$, Jean $\mathrm{PH}$, Laurence $\mathrm{S}$, Rebecca S, Guy VM, Hans S, Alain P'C. Efficacy of resident training in smoking cessation: A randomized, controlled trial of a program based on application of behavioral theory and practice with standardized patients. Annals of Internal Medicine. 2002; 136: 429-37.

9. Tobias E, and Christoph J. Motivation for smoking cessation: What role do doctors play? Swiss Medicine Weekly.2001; 131:521-526.

10.El-Zanaty F, and Way A (2009). Egypt Demographic and Health Survey. Cairo, Egypt: Ministry of Health and Population, National Population Council, El-Zanaty and Associates and USAID and UNICEF;2008.

11.WHO (2008). WHO report on the global tobacco epidemic: The MPOWER Package. Geneva World Health Organization;2008.

12. The Population Council. The Egyptian Cabinet; Information and Decision Support Center (IDSC). Survey of Young People in Egypt (Preliminary Report-February) 2010 P.8

13. Allam MF, and Abd Elaziz KM. Role of members of university students' unions in tobacco prevention. J Prev Med Hyg2007; 48: 136-40.

14.Almutairi KM. Tobacco prevalence among Health Sciences College students (HSC): Riyadh, Saudi Arabia. World Family Medicine Journal.2010; 8 (7): 10-4.

15.Abolfotouh MA, Bassiouni FA, Mounir GM, Fayyad RCh. Health-related lifestyles and risk behaviors among students living in Alexandria University Hostels. Eastern Mediterranean Health Journal.2007; 13: 376-91.

16. Nassar $\mathrm{H}$. The economics of tobacco in Egypt: A new analysis of demand. Health, Nutrition and Population Discussion Paper. Washington DC, International bank for reconstruction and development / World Bank (Economics of Tobacco Control Paper No. 8);2003.

17. Youssef RM, Abou-Khatwa SA, Fouad 
HM Prevalence of smoking and age of initiation in Alexandria, Egypt. Eastern Mediterranean Health Journal.2002; 8 (45): 626-37.

18. Yorulmaza F Z, Aktürkb N, Dagdevirenb A. Smoking among adolescents: relation to school success, socioeconomic status, nutrition, and self-esteem. Swiss Medicine Weekly.2002; 132: 449-54.
19.Public Health Research Consortium. A Review of Young People and Smoking in England. Final Report. [cited 2009]. Available from:: www.york.ac.uk/phrc.

20.Glantz SA, and Jamieson P. Attitudes toward secondhand smoke, smoking, and quitting among young people. Pediartics.2000;106 (6): E82. 